Table 1. Outcomes at 12 months among patients with RA who initiated the first biologic

\begin{tabular}{lccr}
\hline & $\begin{array}{c}\text { Moderate-RA } \\
(\mathbf{n}=\mathbf{2 6 4})\end{array}$ & $\begin{array}{c}\text { Severe-RA } \\
(\mathbf{n = 2 1 9 )}\end{array}$ & $P$-Value \\
\hline Remission, $n(\%)$ & $111(50)$ & $45(23)$ & $<0.0001$ \\
Low disease activity, $n(\%)$ & $151(59)$ & $74(35)$ & $<0.0001$ \\
Change in DAS from baseline $\geq 1.2, n(\%)$ & $168(66)$ & $164(78)$ & 0.0049 \\
HAQ-DI change $>0.22, n(\%)$ & $98(53)$ & $83(52)$ & 0.7974 \\
Change in DAS28 from baseline, mean (SD) & $-1.4(1.3)$ & $-2.2(1.5)$ & $<0.0001$ \\
Change in HAQ-DI from baseline, mean (SD) & $-0.29(0.57)$ & $-0.30(0.66)$ & $<0.0001$ \\
Change in fatigue from baseline, mean (SD) & $-0.98(3.2)$ & $-1.11(3.2)$ & $<0.0001$ \\
Change in sleep from baseline, mean (SD) & $-0.85(3.6)$ & $-1.05(3.9)$ & 0.0004 \\
\hline
\end{tabular}

Disclosure of Interests: Nancy Guo: None declared, Xiuying Li: None declared, Mohammad Movahedi: None declared, Angela Cesta: None declared, Claire Bombardier Grant/research support from: OBRI was funded by peer reviewed grants from ClHR (Canadian Institute for Health Research), Ontario Ministry of Health and Long-Term Care (MOHLTC), Canadian Arthritis Network (CAN) and unrestricted grants from: Abbvie, Amgen, Aurora, Bristol-Meyers Squibb, Celgene, Hospira, Janssen, Lilly, Medexus, Merck, Novartis, Pfizer, Roche, Sanofi, \& UCB.

Acknowledgment: : Dr. Bombardier held a Canada Research Chair in Knowledge Transfer for Musculoskeletal Care and a Pfizer Research Chair in Rheumatology

DOI: 10.1136/annrheumdis-2021-eular.1125

\section{POS0450 \\ INCIDENCE RATES OF DIFFICULT-TO-TREAT RHEUMATOID ARTHRITIS IN REAL-WORLD CLINICAL PRACTICE}

Y. Hirano ${ }^{1}$, J. Hasegawa ${ }^{1}$, H. Kosugiyama ${ }^{2}$, D. Kihira ${ }^{2}$, K. Hattori' ${ }^{2}{ }^{1}$ Toyohashi Municipal Hospital, Rheumatology, Toyohashi, Japan; ${ }^{2}$ Nagoya University Graduate School of Medicine, Orthopaedic Surgery and Rheumatology, Nagoya, Japan

Background: A definition of difficult-to-treat rheumatoid arthritis (D2T RA) was recently proposed by the European League Against Rheumatism (EULAR) [1]. However, information on the incidence rates of D2T RA in real-world clinical practice is lacking.

Objectives: The aim of this retrospective cross-sectional study was to evaluate the incidence rates of D2T RA in clinical practice in Japan.

Methods: Data from the Toyohashi RA database (TRAD) was used. The TRAD is a collection of single-center retrospective data. Patients with RA who fulfilled the following three requirements were included in this study: (1) had been treated with $>1$ biological or targeted synthetic disease-modifying antirheumatic drug (b/ tsDMARD); (2) >1 year had passed since b/tsDMARD treatment was initiated; and (3) regularly visited our institute at the time of investigation. The number of targeted patients was 363 . The criteria of D2T RA used in this study were modified from the EULAR definition for simplification of the investigation as follows: (a) $\geq 2$ b/t DMARDs with different mechanisms of action had been administered; (b) at least moderate disease activity (DAS28-ESR $>3.2$ or clinical disease activity index [CDAl] > 10) at the time of investigation; and (c) $7.5-\mathrm{mg} /$ day of prednisolone (PSL) or more was administered at the time of investigation. In this study, D2T RA was defined as criteria (a) + (b) or (a) + (c) or (a) + (b) + (c). The 363 patients were categorized into four groups as follows: group A, DT2 RA; group B, patients with RA who had been treated with $\geq 2 \mathrm{~b} /$ tsDMARDs and did not fulfill the D2T RA definition; group $C$, RA patients who had been treated with one kind of b/tsDMARD with the same mechanism of action (e.g., two kinds of tumor necrosis factor inhibitors) and fulfilled either or both criteria (b) and (c); and group D, patients with RA who had been treated with one kind of b/tsDMARD with the same mechanism of action (e.g., a tumor necrosis factor inhibitors or two interleukin 6 inhibitors) and did not fulfill either or both criteria (b) and (c). The incidence rates of D2T RA were calculated, and the patients' characteristics at the time of initiation of the b/tsDMARD treatment were compared between the groups.

Results: The number of patients in groups A, B, C, and D were $34,53,94$, and 182 , respectively. Of all the patients included in this study, $9.4 \%$ were categorized into group $A$, those with D2T RA, and $39.1 \%$ were treated with $\geq 2 \mathrm{~b} / \mathrm{tsD}$ MARDs and categorized into group A (Fig 1). The patients' characteristics were as follows (group $A / B / C / D)$ : mean age (57.1/54.3/61.4/56.2 years), RA duration (10.0/6.7/13.8/8.2 years), \%Steinbrocker stage III+IV (\%; 84.0/60.0/77.3/54.3), $\%$ Steinbrocker class $3+4$ (\%; 68.0/33.3/43.4/23.0), methotrexate (MTX) concomitant rate $(\% ; 79.4 / 92.5 / 74.5 / 91.8)$, PSL concomitant rate $(\% ; 91.2 / 52.8 / 55.3 / 43.4)$, DAS28-ESR score (5.5/5.0/5.5/4.7), and CDAI score (12.3/13.7/22.7/16.9). There were statistically significant differences in RA duration, \%stage III+IV, \%class $3+4$ and PSL concomitant rate between group $A$ and $B$.

Conclusion: D2T RA occurred in $9.4 \%$ of patients treated with b/tsDMARDs. Incidence rate was increased to $39.1 \%$ after the treatment with $\geq 2 \mathrm{~b} / \mathrm{tsDMARDs}$. The patients with D2T RA tended to be older, have a long RA duration, be treated without concomitant MTX, be treated with concomitant PSL, and have higher disease activity at the time of starting the b/tsDMARD treatment. The baseline patient characteristics in group $C$ were similar to those in group $A$. In the future, we suggest that patients with D2T RA be included in group C.

\section{REFERENCES:}

[1] Nagy et al. Ann Rheum Dis 2021; 80: 31-35.
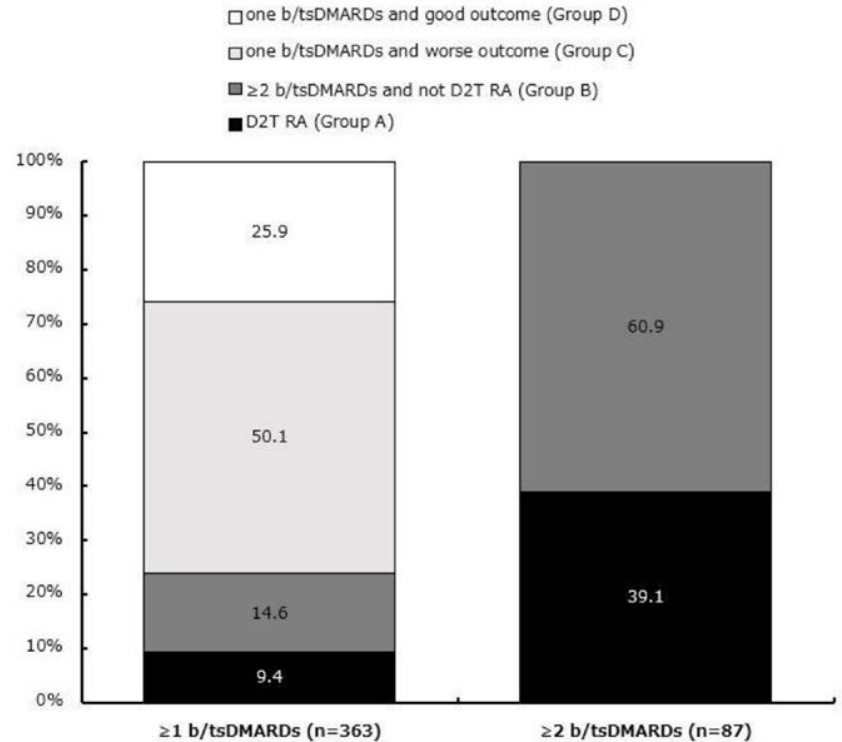

Figure1. Incidence rate of difficult-to-treat rheumatoid arthritis

Disclosure of Interests: None declared DOI: 10.1136/annrheumdis-2021-eular.1221

\section{POS0451 SERUM FETUIN-A AND VISFATIN LEVELS IN WOMEN WITH RHEUMATOID ARTHRITIS DEPENDING ON DISEASE ACTIVITY}

Y. Akhverdyan ${ }^{1}$, B. Zavodovsky', E. Papichev' ${ }^{1}$, J. Polyakova ${ }^{1}$, L. Seewordova ${ }^{1}$. ${ }^{1}$ Federal State Budgetary Institution «Research Institute of Clinical and Experimental Rheumatology named after A.B. Zborovsky», Joint Diseases Treatment and Prevention Laboratory, Volgograd, Russian Federation

Background: In recent years, the systemic effects of a number of cytokines have been actively studied, in particular, fetuin- $A$ is considered a negative protein of the acute phase response, and visfatin, on the contrary, affects the activation of the cytokine cascade and has a pro-inflammatory effect. Taking into account that women suffer from rheumatoid arthritis (RA) more often, we investigated the levels of fetuin-A and visfatin in the blood serum of females in comparison with a group of healthy individuals and depending on the activity of the disease.

Objectives: to study the levels of fetuin-A and visfatin in the blood serum of women suffering from RA, depending on the activity of the disease

Methods: The study included 110 women with RA and 30 apparently healthy individuals. The inclusion criteria were: a diagnosis of RA verified based on the criteria of the American College of Rheumatology/European Anti-Rheumatic League (ACR/EULAR) 2010. The patients' age ranged from 18 to 90 years. The control group included 30 conventionally healthy individuals. Serum fetuin-A and visfatin levels were determined by indirect enzyme-linked immunosorbent assay using commercial kits. RA activity was determined by the DAS28-CRP index. Activity $0-\mathrm{I}$ was in $33(30 \%)$ patients, grade II in $67(60.9 \%)$, grade III in $10(9.09 \%)$ patients.

Results: The normal level of fetuin-A was calculated using the formula $M \pm 2 \sigma$ in the group of conventionally healthy individuals and ranged from 653.55 to $972.19 \mu \mathrm{g} / \mathrm{ml}$. In patients with grade 0 -I RA activity according to DAS28, the mean serum fetuin-A level was $843.92 \pm 130.73 \mu \mathrm{g} / \mathrm{ml}$, in patients with grade II activity $-742.37 \pm 98.85 \mu \mathrm{g} / \mathrm{ml}$, with III the degree of activity $-663.9 \pm 123.7 \mu \mathrm{g} /$ $\mathrm{ml}(\mathrm{p}<0.001)$.

The average level of visfatin in the blood serum in healthy individuals was $2.43 \pm 0.17 \mathrm{ng} / \mathrm{ml}$. The level of normal values of visfatin in healthy individuals, defined as $M \pm 2 \sigma$, ranged from 0 to $5.07 \mathrm{ng} / \mathrm{ml}$. The average level of visfatin in patients with RA was $6.27 \pm 0.18 \mathrm{ng} / \mathrm{ml}$, which is significantly higher than in healthy individuals $(p<0.001)$.

In patients with 0-I degree of RA activity according to DAS28, the average level of visfatin in blood serum was $4.94 \pm 0.02 \mathrm{ng} / \mathrm{ml}$, in patients with degree II activity $-5.08 \pm 0.02 \mathrm{ng} / \mathrm{ml}$, with III degree of activity $-6.82 \pm 0.23 \mathrm{ng} / \mathrm{ml}(p<0.001)$ 